\title{
Assessment of indeterminate melanocytic choroidal tumours with optical coherence tomography: A cohort study
}

\author{
Steven Garnier ${ }^{1}$, J ean-Daniel Grange ${ }^{1}$, Laurent Kodjikian ${ }^{1,2}$ \\ 1. University of Lyon, Department of Ophthalmology, Croix Rousse Hospital, Lyon, France. 2. University of Lyon, CNRS \\ UMR-5510 MATEIS, Claude Bernard University Lyon, France \\ Correspondence: Pr. Laurent Kodjikian. Address: Croix-Rousse University Hospital, Department of Ophthalmology, \\ 103, grande rue de la Croix-Rousse, Lyon 69004, France. Telephone: 33-472-071-718. Email: \\ kodjikian.laurent@wanadoo.fr.
}

Received: June 4, 2012

Accepted: July 31, 2012

Online Published: December 24, 2012

DOI : $10.5430 /$ jbgc.v3n1p75

URL: http://dx.doi.org/10.5430/jbgc.v3n1p75

\begin{abstract}
Background: It is difficult to differentiate large choroidal naevi from small melanomas. The management of patients with such 'indeterminate melanocytic tumours' is controversial. This is because over-treatment of naevi can cause unnecessary visual loss whereas delayed treatment of melanoma may have fatal consequences. Several studies have shown that serous retinal detachment overlying an indeterminate melanocytic choroidal tumour predicts growth of these tumours; however, these studies have mostly been based on ophthalmoscopy. Optical coherence tomography (OCT) facilitates the detection of subtle retinal detachment. It is not known, however, whether minimal retinal detachment is clinically relevant. The aim of our study was to evaluate OCT as a tool for predicting growth of indeterminate melanocytic choroidal tumours.
\end{abstract}

Methods: Forty-five patients with a recently-detected, indeterminate melanocytic choroidal tumour were examined with OCT and the findings were correlated with subsequent tumour growth.

Results: After a mean follow-up of 15 months, 9 of 17 tumours with SRF showed growth as compared to 1 out of 28 tumours without SRF. Tumours with SRF increased in thickness by an average of $+0.26 \mathrm{~mm}$ [ $95 \%$ confidence interval (CI): -0.06 to +0.57 ] as compared to a mean decrease of $-0.12 \mathrm{~mm}$ [95\% CI : -0.22 to -0.03 ] in tumours without SRF. Of the eight tumours requiring treatment because of observed growth, seven showed overlying SRF as compared to none of the tumours without SRF.

Conclusions: OCT is useful in predicting growth of indeterminate melanocytic choroidal tumours.

\section{Key words}

Malignant melanoma, Naevus, Choroid, Optical coherence tomography, Tomography, Optical coherence

\section{Background}

Large choroidal naevi can be clinically indistinguishable from small choroidal melanomas ${ }^{[1]}$. This difficult situation is rather different from that of medium-sized and large melanomas, which can be diagnosed correctly in more than 99\% of cases ${ }^{[2]}$. Clinical features predictive of tumour growth were described over twenty years ago and include: tumour thickness exceeding $2 \mathrm{~mm}$; confluent orange pigment; serous retinal detachment; symptoms (blurred vision or loss of peripheral vision, floaters or flashing lights); and contact with optic disc ${ }^{[3,4]}$. The likelihood of tumour growth is related to the number of such risk factors that are present. The presence of subretinal fluid (SRF) overlying the tumour 
is a strong predictor of tumour growth ${ }^{[3-5]}$; however, subtle retinal detachment can be difficult to see ophthalmoscopically. Optical coherence tomography (OCT) has greatly enhanced the detection of retinal pathology ${ }^{[6]}$. Furthermore, OCT has been shown to facilitate the demonstration of subtle retinal detachment overlying small melanocytic tumours ${ }^{[7,8]}$. It is not known, however, whether minimal retinal detachment, detected with OCT, is predictive of tumour growth.

The aim of this study was to determine whether OCT could reliably predict growth of indeterminate, melanocytic choroidal tumours by detecting SRF over such lesions.

\section{Methods}

Consecutive patients were recruited prospectively for a twelve-month period commencing in May 2006. The inclusion criteria were: the presence of a posterior choroidal melanocytic tumour of indeterminate malignancy; tumour detection less than one year before the first visit to our hospital; thickness not exceeding $3.0 \mathrm{~mm}$; and lack of multiple risk factors (i.e., orange pigment, absence of drusen and contact with optic disc margin). These patients were managed by observation and were reviewed every 3 months. Assessments at each visit included: history, best corrected visual acuity, full ophthalmic examination; fundus photography (colour and red-filtered), and B-scan ultrasonography, which were all performed by the same examiner (BJL). Time-domain OCT examination was performed by the same examiner (SG) using the StratusOCT ${ }^{\circledR}$ (from Carl Zeiss-Meditec). SRF overlying the tumour was considered to be present when OCT showed a region of low reflectivity between the outer retinal layer and the retinal pigment epithelium (see Figure 1 (b)). Multiple scans "LINE" (512 A-scans per line) were used to scan the tumour surface as well as the anterior, posterior and inferior tumour margins (see Figure 1a). SRF was categorised as being present or absent. Examiner reviewing the patient (JDG) was masked to the OCT results with respect to presence or absence of SRF. Institutional board approval and patient consent were obtained.

Figure 1. Melanocytic tumour of indeterminate malignancy located infero-temporally in the right eye. The tumour had a largest basal diameter of $5.0 \mathrm{~mm}$ and a thickness of $1.8 \mathrm{~mm}$

(a) fluorescein angiogram showing irregular pigmented epithelium

(b) OCT image of inferior tumour margin showing SRF

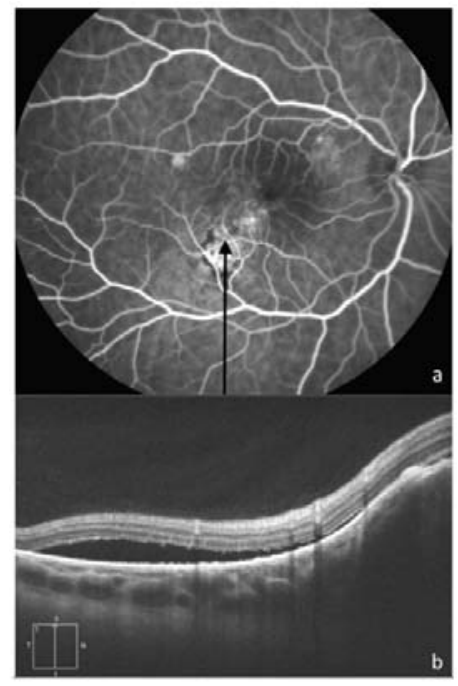

\section{Statistical analysis}

The main outcomes were increase in tumour thickness and diameter as measured by ultrasonography as well as by colour photography and red-free photography. The tumour volume was estimated by the formula of a hemi-ellipsoid volume, because of the dome-shaped geometry of these small tumours ${ }^{[9]}$.

Statistical analysis was performed after a minimum follow-up of one year. Comparability of groups is described in Table 1. Student t-test was used to compare differences between the two groups. No patients were lost to follow-up and data were complete when the study was closed. 
A table of contingency is drawn (see Table 2) to approach predictive values, specificity and sensitivity. Growing tumours showing OCT-SRF are called true positive (TP), non-growing tumours showing OCT-SRF are false positive (FP), non-growing tumours without OCT-SRF are true negative (TN) and growing tumours without OCT-SRF are called false negative (FN). Sensitivity measures the proportion of correctly identified growing tumours: it is the ratio of TP to growing tumours. Specificity measures the proportion of correctly identified non-growing tumours: it is the ratio of TN to non-growing tumours. Positive predictive value is the proportion of growing tumours (TP) among tumours with OCT-SRF. Negative predictive value is the proportion of non-growing tumours (TN) among tumours without OCT-SRF.

\section{Results}

\subsection{Study group}

Forty-five eyes of 45 patients were included in the study between May 2006 and April 2007. The patients (23 male, 22 female) had mean age of 61 years. The characteristics of the total study group are summarized in Table 1. Seventeen out of 45 (38\%) tumours showed SRF. The median follow-up was 14 months (range: 2.5 - 26). During the observation period, 9/45(20\%) tumours were considered to have grown on the basis of ultrasonography. All patients showing any significant tumour growth were treated with proton beam radiotherapy.

Table 1 shows no significant differences in the tumour thickness and diameter between tumours with SRF and those without this finding. Tumours with SRF also showed a higher prevalence of risk factors for tumour growth.

Table 1. Group Comparability Data

\begin{tabular}{|c|c|c|c|}
\hline & \multicolumn{2}{|c|}{ Sub Retinal Fluid } & \multirow{2}{*}{$\begin{array}{l}\text { Total study group } \\
\mathrm{n}=45\end{array}$} \\
\hline & present $n=17$ & absent $n=28$ & \\
\hline $\begin{array}{l}\text { Clinical retinal detachment } \\
\text { (fundus ex.) }\end{array}$ & $4(24 \%)$ & $0(0 \%)$ & $4(9 \%)$ \\
\hline No clinical risk factor & $4(24 \%)$ & 15 (53\%) & $19(42 \%)$ \\
\hline 1 risk factor & 5 (29\%) & 9 (32\%) & $14(31 \%)$ \\
\hline 2 risk factors & $6(35 \%)$ & $3(11 \%)$ & $9(20 \%)$ \\
\hline 3 risk factors or more & $2(12 \%)$ & $1(4 \%)$ & $3(7 \%)$ \\
\hline Drusen & 7 (41\%) & $12(43 \%)$ & $19(42 \%)$ \\
\hline$>2 \mathrm{~mm}$ thick & $8(32 \%)$ & $6(21 \%)$ & $14(31 \%)$ \\
\hline $\begin{array}{l}\text { INITIAL THICKNESS } \\
\text { Mean (median) [Range] }\end{array}$ & $\begin{array}{l}2.08 \mathrm{~mm}(1.9) \\
{[1.2-3.5]}\end{array}$ & $\begin{array}{l}1.78 \mathrm{~mm}(1.7) \\
{[0.8-3.0]}\end{array}$ & $\begin{array}{l}1.84 \mathrm{~mm}(1.8) \\
{[0.8-3.5]}\end{array}$ \\
\hline $\begin{array}{l}\text { INITIAL DIAMETER (LTD) } \\
\text { Mean (median) [Range] }\end{array}$ & $\begin{array}{l}6.07 \mathrm{~mm}(6.0) \\
{[4.0-8.0]}\end{array}$ & $\begin{array}{l}5.49 \mathrm{~mm}(5.0) \\
{[2.5-8.0]}\end{array}$ & $\begin{array}{l}5.72 \mathrm{~mm}(5.8) \\
{[2.5-8.0]}\end{array}$ \\
\hline $\begin{array}{l}\text { FOLLOW-UP } \\
\text { Mean (median) [Range] }\end{array}$ & $\begin{array}{l}310 \text { days (293) } \\
\text { [76-696] }\end{array}$ & $\begin{array}{l}533 \text { days }(548) \\
{[360-801]}\end{array}$ & $\begin{array}{l}448 \text { days (415) } \\
\text { [76-801] }\end{array}$ \\
\hline
\end{tabular}

\subsection{Main results}

In the presence of SRF, the tumour thickness increased by an average of $+0.26 \mathrm{~mm}$ [95\% CI : -0.06 to +0.57$]$ as compared to mean decrease of $-0.12 \mathrm{~mm}$ [95\% CI : -0.22 to -0.03 ] in tumours without SRF (Student t-test, $\mathrm{p}=.039$ ). Tumours with SRF showed a mean increase in largest tumour diameter (LTD) of $+0.81 \mathrm{~mm}$ [95\% CI: +0.15 to +1.46 ] whereas in the absence of SRF the LTD decreased by an average of $-0.10 \mathrm{~mm}$ [95\% CI: -0.33 to +0.12$]$ (Student $t$-test, $p=.024$ ) (see Table 1). 
By the close of the study, 9/45 (20\%) tumours were treated. Eight of these nine tumours showed SRF with OCT. The tumour without SRF that was treated showed an increase in tumour thickness of $+0.2 \mathrm{~mm}$ after a follow-up of 12 months, without change in basal diameter, this tumour was the thickest of the group (3.0mm initially). The remaining 27 tumours without SRF did not need any treatment as no growth has been observed. Only 8/17 (47\%) tumours with SRF grew, indicating a low positive predictive value. Conversely, only one tumour grew in the absence of OCT-SRF: the negative predictive value of OCT was therefore $96 \%$ for 12 months, indicating a high predictive negative value.

Table 2. Table of contingency of the main outcome results

\begin{tabular}{lllll}
\hline & Tumour growth & & & \\
\cline { 2 - 5 } & Absent & Present & total & Predictive values \\
\hline SRF absent & 27 & 1 & 28 & Negative 96\% \\
SRF present & 9 & 8 & 17 & Positive 47\% \\
Total & 36 & 9 & 45 & \\
\hline \multicolumn{5}{l}{} \\
\hline
\end{tabular}

Figure 2. Tumour dimensions at the first visit and at latest follow-up

$\mathrm{y}$-axis is thickness, $\mathrm{x}$-axis is largest basal diameter

Black spots $=$ SRF absent, White spots $=$ SRF present

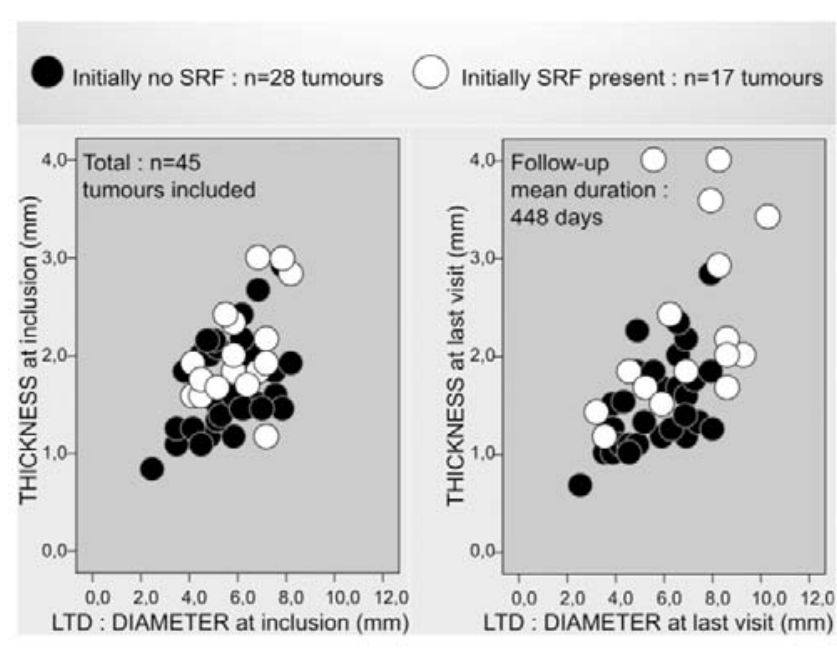

\subsection{I nter-examination repeatability of OCT}

All 28 tumours without SRF initially were free of SRF at follow-up. Conversely, in three out of 17 (18\%) tumours, SRF that was present at initial examination was no longer detectable at follow-up. The dimensions of these three tumours remained unchanged, considering the repeatability with ultrasonography.

\section{Discussion}

The main finding of our study is that detection of SRF with OCT was predictive of tumour growth. No tumours showed growth in the absence of SRF and no tumours without SRF on initial examination subsequently developed retinal detachment.

The main strength of our study is the prospective data acquisition. To our knowledge, previous studies collected data only retrospectively ${ }^{[6-8]}$. Our study was also enhanced by the use of ultrasonography to measure tumour dimensions and detect growth. Repeatability was increased by our policy of having all scans performed by the same examiner, but authors consider that reliability of ultrasonography should be demonstrated. The main weakness is the short follow-up so that more patients may have developed detectable tumour growth after the close of the study. Observing these indeterminate tumours, visits are frequent: one year could represent a long period between two visits. Other weakness is the limited number of patient but we have to consider these tumours as rare. 
In 1997, Schaudig demonstrated that OCT was more sensitive in detecting SRF than ophthalmoscopy ${ }^{[8]}$. In 2005, Shields and associates analyzed 120 naevi and detected SRF in only $3 \%$ of these ${ }^{[10,11]}$. The author described other common OCT abnormalities overlying the tumour, which included retinal degeneration (42\%), thinning (22\%), oedema (15\%) and pigment epithelial detachment (13\%). In 2004, Muscat et al compared 20 choroidal melanomas with 40 "presumed naevi under observation" with respect to the presence of SRF ${ }^{[12]}$. OCT showed all melanomas to have overlying SRF and these included eight tumours with SRF that could not be detected ophthalmoscopically. In Muscat's study, OCT showed SRF in 12/40 (30\%) naevi, such fluid not being detectable clinically in most cases. In 2004, Espinoza reported tumour growth in 2/21 (10\%) of tumours without SRF as compared to six out of 12 (50\%) of tumours with SRF ${ }^{[13]}$. The results of Muscat and Espinoza are similar to ours.

Other risk factors are well described ${ }^{[14-17]}$. Further studies are required to determine how many melanocytic choroidal tumours without SRF on ophthalmoscopy have SRF on OCT and how many of these subsequently show growth. Furthermore, among a set of factors, which, in their sum, might better predict outcome, OCT-SRF has to be assessed in a multivariate analysis where risk factors are included. In such an analysis, orange pigment and clinical ophthalmoscopic retinal detachment could represent confusion factors and could be isolated.

This study did not provide results to evaluate the prognostic importance of location of SRF. In our series, macular SRF seems to be more frequent in case of posterior tumours. Macular detachment occurring with naevus is described ${ }^{[13]}$. Macular SRF leads to vision loss and could justify treatment of the exudation to increase vision.

In conclusion, our study demonstrates the sensitivity of OCT in detecting SRF overlying small choroidal melanocytic tumours. In this study, the presence of OCT-SRF seems to be related to tumour growth. These first results need to be repeated in another studies to determine specificity and sensitivity with an adequate statistical method and further studies using multivariate analyses need to be performed to assess the relevance of OCT-SRF as an independent risk factor.

\section{References}

[1] Zografos L. Tumeurs intraoculaires. Société Française d’Ophtalmologie Masson, Paris. 2002: 65-116.

[2] Collaborative Ocular Melanoma Study Group. Accuracy of diagnosis of choroidal melanomas in the Collaborative Ocular Melanoma Study. COMS report No 1. Arch Ophthalmol. 1997; 115: 1537-44. PMid:9400787 http://dx.doi.org/10.1001/archopht.1997.01100160707007

[3] Augsburger JJ, Schroeder RP, Shields JA et al. Clinical parameters predictive of enlargement of melanocytic choroidal lesions. Br J Ophthalmol. 1989; 73: 911-7. PMid:2605146 http://dx.doi.org/10.1136/bjo.73.11.911

[4] Shields C, Furuta M, Berman EL et al. Choroidal nevus transformation into melanoma: analysis of 2514 consecutive cases. Arch Ophthalmol. 2009; 127: 981-7. PMid:19667334 http://dx.doi.org/10.1001/archophthalmol.2009.151

[5] Singh AD, Mokashi AA, Bena JF et al. Small choroidal melanocytic lesions: features predictive of growth. Ophthalmology. 2006; 113: 1032-9. PMid:16650475 http://dx.doi.org/10.1016/j.ophtha.2006.01.053

[6] Puliafito CA. Optical coherence tomography of ocular diseases. Slack Incorporated, Thorofore 1994.

[7] Muscat S, Srinivasan S, Sampat V, et al. Optical coherence tomography in the diagnosis of subclinical serous detachment of the macula secondary to a choroidal nevus. Ophthalmic Surg Lasers. 2001; 32: 474-6. PMid:11725771

[8] Schaudig U, Hassenstein A, Bernd A, et al. Limitations of imaging choroidal tumors in vivo by optical coherence tomography. Graefes Arch Clin Exp Ophthalmol. 1998; 236: 588-592. PMid:9717654 http://dx.doi.org/10.1007/s004170050126

[9] Singh AD, Terman S, Sculley L. Estimating choroidal melanoma volume: comparison of methods. Ophthalmology. 2007; 114: 1212-1216. PMid:17320179 http://dx.doi.org/10.1016/j.ophtha.2006.08.056

[10] Shields CL, Mashayekhi A, Shields JA, et al. Optical coherence tomography of choroidal nevus in 120 patients. Retina. 2005; 25: 243-252. PMid:15805899 http://dx.doi.org/10.1097/00006982-200504000-00001

[11] Shields CL, Materin MA, Shields JA, et al. Review of optical coherence tomography for intraocular tumors. Curr Opin Ophthalmol. 2005; 16: 141-154. PMid:15870570 http://dx.doi.org/10.1097/01.icu.0000158258.01681.40

[12] Muscat S, Park S, Kemp E, et al. Secondary retinal changes associated with choroidal naevi and melanomas documented by optical coherence tomography. Br J Ophthalmol. 2004; 88: 120-1244. PMid:14693788 http://dx.doi.org/10.1136/bjo.88.1.120

[13] Espinoza G, Rosenblatt B, Harbour JW. Optical coherence tomography in the evaluation of retinal changes associated with suspicious choroidal melanocytic tumors. Am J Ophthalmol. 2004; 137: 90-95. http://dx.doi.org/10.1016/S0002-9394(03)00868-7 
[14] Duquesne N, Grange JD. Choroidal nevi associated with serous macular detachment. J Fr Ophtalmol. 2002; 25: 393-401. PMid:12011744

[15] Souckova I, Soucek P. Optical coherence tomography in benign and malignant melanocytic tumors. Cesk Slov Oftalmol. 2008; 64: 228-30. PMid:19110962

[16] Chin K, Finger PT. Autofluorescence characteristics of suspicious choroidal nevi. Optometry. 2009; 80: 126-30. PMid:19264288 http://dx.doi.org/10.1016/j.optm.2008.07.018

[17] Shields CL, Pirondini C, Bianciotto C et al. Autofluorescence of choroidal nevus in 64 cases. Retina. 2008; 28: 1035-43. PMid:18779708 http://dx.doi.org/10.1097/IAE.0b013e318181b94b 